\title{
Asma Anacı Çeliklerinde Kök Oluşum Yoğunluğu Yerlerinin Saptanması
}

\author{
Fatime CAN1, İsmail YENILMEZ2 ${ }^{\mathscr{8}}$, Salih ÇELİK ${ }^{3}$
}

1,3Namı Kemal Üniversitesi, Ziraat Fakültesi, Bahçe Bitkileri Bölümü, Tekirdağ, ${ }^{2}$ Eskişehir Teknik Üniversitesi, Fen Fakültesi, İstatistik Bölümü, Eskişehir, Türkiye

${ }^{1}$ https://orcid.org/0000-0002-1585-889X, ${ }^{2}$ https://orcid.org/0000-0002-3357-3898, ${ }^{3}$ https://orcid.org/0000-0003-3180-8339

৫: ismailyenilmez@eskisehir.edu.tr

\section{ÖZET}

Bu çalışmada, çeliklerde oluşan köklerin, çeliğin hangi kısmında ve ne yoğunlukta oluştuğu araştırılmıştır. Ayrıca asma anacı çelikleri arasında kök oluşum yoğunluğu açısından bir farklılığın olup olmadığı incelenmiştir. Tekirdağ Bağcılık ve Araştırma Enstitüsü'nden temin edilen SO4, 5BB, Lot ve 8B asma anacı çelikleri kullanılmış ve deneme bu enstitüde yürütülmüştür. Çelikler $15 \mathrm{~cm}$ sıra arası (SA) ve sıra üzeri (SÜ) mesafe ile hazırlanan derin kum sandıklarına 3 Mart 2017'de dikilmiştir. Yaprak dökümünden sonra 15 Kasım 2017'de köklü çelikler sandıklardan çıkarılıp ölçüm ve sayım yapılmıştır. Gözün solundan, sağından, karşısından ve hemen altından ölçümler yapılmıştır. Dikkate alınan kriterler kök sayısı, uzunluğu, ağırlığı ve kalınlığıdır. Literatürde sıklıkla raslatan tek faktörlü deney tasarımı modelleri yerine iki faktörlü faktöriyel deney tasarımı modeli kullanılmıştır. Böylece hem boğumlar arası farklılıklar hem de anaçlar arasındaki farklılar ana faktörler olarak ele alınabilmiş ve incelenmiştir. Ayrıca iki faktörlü deney tasarımı kullanımı, anaç ve boğum ana faktörlerinin etkileşimlerinin de incelenebilmesini sağlamıştır. Tüm bulgular özet tablolar halinde sunulmuş ve yorumlanmıştır. Sonuç olarak; kök sayısı, uzunluğu, ağırlığı ve kalınlığı bakımından boğumlar ve anaçlar arasında istatistiksel farklılıklar olduğu ortaya konmuştur.

\section{Determination of Root Formation Density Places on Rootstock Cuttings}

\section{ABSTRACT}

In this study, the internodes locations of the roots formed in cuttings were investigated. In addition, it has been investigated whether there is a difference in root formation density for grapevine types. $\mathrm{SO} 4,5 \mathrm{BB}$, Lot and 8B grapevine rootstocks obtained from Tekirdağ Viticulture and Research Institute were used and the experiment was conducted in the same institute. The cuttings were planted in deep sand boxes prepared with $15 \mathrm{~cm}$ row spacing (RS) and intra-row spacing (IS) on March 3, 2017. After defoliation, cuttings were removed from the boxes and measured on November 15, 2017. Root measurements were made from the left, right, opposite and just below the internodes. The criteria used were the number of roots, root length, root weight and root thickness. The two-factor factorial design model was used instead of the single-factor design model, which frequently appeared in the literature. Thus, the differences between the internodes and the differences between the grapevine types could be considered as the main factors examined. In addition, the use of two-factor experimental design allowed to investigate the interaction of grapevine types and internodes. All findings were presented and interpreted. As a result there were statistical differences between the internodes and rootstocks in terms of number of roots, root length, root weight and root thickness.

\section{Araştırma Makalesi}

\section{Makale Tarihçesi}

Geliş Tarihi : 12.11 .2019

Kabul Tarihi : 20.02.2020

Anahtar Kelimeler
SO4
5B
Lot
8B
Kök yoğunluğu

\section{Research Article}

$\begin{array}{ll}\text { Article History } & \\ \text { Received } & : 12.11 .2019 \\ \text { Accepted } & : 20.02 .2020\end{array}$

Keywords

$\mathrm{SO} 4$

$5 \mathrm{~B}$

Lot

$8 \mathrm{~B}$

Root density

To Cite : Can F, Yenilmez İ, Çelik S 2020. Asma Anacı Çeliklerinde Kök Oluşum Yoğunluğu Yerlerinin Saptanması. KSÜ Tarım ve Doğa Derg 23 (3): 561-567. DOI: 10.18016/ksutarimdoga.vi.645752. 


\section{GİRIŞ̧}

Bağ alanı yönünden dünya ülkeleri arasında ilk sıralarda yer alan Türkiye'de de, diğer ülkelerde olduğu gibi, yeni bağ alanlarının oluşumu sürecinde asma fidanlarına ihtiyaç duyulmaktadır. Bu duruma ek, filoksera zararlısı ve kuraklık gibi sorunlardan dolayı bağcılıkta aşılı anaç kullanılma zorunluluğu gün geçtikçe kaçınılmaz hale gelmektedir. $\mathrm{Bu}$ bağlamda farklı affinite ve adaptasyon özelliklerine sahip olan birçok anaç elde edilmiştir. Köklü anaç ve aşlı köklü fidan kullanımı bağ kurulurken tercih edilmektedir. Bu süreçte belli standartlar göz önünde bulundurulur (Anonim, 1983; Anonim, 1988; Anonim, 1990; Anonim, 1992 ve Çelik ve ark., 1998). Anaç çeliklerinin köklenmesi, anaçlara göre farklılık gösterebilmektedir (Atilla, 1985; Barış, 1983; Barlass ve Skene, 1980). Köklenme özelliklerinin anaçlara göre değişebileceği (Çakır ve ark., 2013) gibi aynı anacın üzerindeki kök oluşum yerlerinde de farklılık görülebileceği bilinmektedir.

Birçok ülkede olduğu gibi Türkiye'de de bağ alanları filoksera zararlısılla bulaşık durumdadır. Bu zararlı asma köklerinde emgi yapmakta ve yapraklarda gal oluşumuna neden olmaktadır. Bu zararlı ile bulaşık bağ alanlarındaki yerli üzüm çeşitlerinden alınan çeliklerin köklendirilmesiyle elde edilen fidanlar ile bağ tesisi yapılamamaktadır. Çünkü filoksera zararlısına karşı Vitis vinifera L. asma türü önemli derecede hassastır (Ruckenbauer ve ark., 1975). Bu nedenle sıklıkla filoksera zararlısına karşı dayanıklı olan Amerikan asma anaçları üzerine aşılı yerli üzüm çeşitleriyle bağlar kurulmaktadır. Bağcılıkta anaçkalem kombinasyonunun asmada vejetatif gelişmeyi etkilediği ifade edilmiştir (Santarosa ve ark., 2015). Bu aşamada aşılı köklü asma fidanı kullanımı, aşılamada seçilen çeşitlerin randımanına bağlı olarak değişkenlik göstermektedir (Aslan ve ark., 2015; Yağcı ve Aydın, 2015; Persuric ve ark., 2015; İşçi ve ark., 2015; Yağcı ve Gökkaynak, 2016). Asma anaçlarının köklendirilmesinde Vitis vinifera türüne ait bazı çeliklerde köklenmelere dair iyi, orta ve zor köklenme özellikleri dikkate alınarak ayrımlar yapılmıştır (Sucu ve Yağcı, 2017). Aynı çalışmada ilgili anaçların aşısızlarının, aşılılara göre daha yüksek randımana sahip olduğu ortaya konmuştur. Belli aşılı asma anacı üretiminde mikoriza uygulamalarının etkileri araştırılmıştır (Eroğlu ve Çelik 2015). Asma anacı fidanlarının köklenmesi, sürgün gelişimi gibi faktörlerin son yıllarda önem kazandiğ 1 vurgulanmıştır (Sabır, 2002). Hidroponik sistemde farklı kültür ortamının etkilerini araştırmak amacıyla Ruggeri 140 (140R) ve Couderc 1616 (1616C) anaçları üzerine omega aşı ile aşılanmış Alfonse Lavallée, üç farklı agregat ortamında kullanılmış; köklenme oranları ve kapasiteleri sunulmuştur. Tarımsal kaya yününde yüksek köklenme oranı olduğu ifade edilmiştir (Şengel ve Ark., 2012). Merzifon Karası üzüm çeşidine en uygun olabilecek anaçların belirlenmesi için on farklı asma anacı kullanılmış; anaç gelişimi için kallus oluşumu, köklenme kapasitesi ve farklı anaçların büyüme üzerine etkisi istatistiksel yöntemlerle incelenmiştir (Köse ve Ark., 2015). Aşılı asma fidanı üretiminde anaç çapının; aşı başarısına,- fidan randımanına ve kalitesine etkileri incelenmiş; aşılı çeliklerin kallus, köklenme performansı ve fidan randımanı değerlendirilmiştir (Cangi ve Etker, 2018). Kapsamlı bir literatür araştırmasıyla çeşitli toprak ortamları ve anaç genotipleri için asma köklerinin kök derinlik dağılımları sunulmuştur (Smart ve Ark., 2006).

$\mathrm{Bu}$ çalışmanın başlıca amacı ise, üretim materyali olarak kullanılan asma anacı çeliklerinde adventif köklerin oluşum yoğunluğu yerlerini saptamak ve farklı anaçların eş kültür ortamındaki kök gelişimlerini yoğunluk açısından ortaya koymaktır. Böylece kök oluşum yoğunluğunun bölgesi ile kök oluşum yoğunluğunun anaç çelik türlerine göre değişimi ortaya konmuştur. Bu bağlamda ikinci bölümde araştırmada kullanılan materyal ve metot paylaşılmıştır. Üçüncü bölümde bulgular sunulmuş ve tartışılmıştır. Son olarak elde edilen sonuçlar sunulmuştur.

\section{MATERYAL ve METOT}

\section{Materyal}

Araştırma, Tekirdağ Bağcılık ve Araştırma Enstitüsü'nde 2017 yılında yürütülmüş olup bitkisel materyaller de buradan temin edilmiştir. Kullanılan materyaller anaçlara ait çelikler olup bu materyallerin serbest kök gelişmesini sağlamak için, çeliklerin üst boğumları dışarıda kalacak şekilde, derin tahta sandıklarda ince dere kumu ortamina dikilmişlerdir. Kullanılan asma anacı çelik çeşitlerinin özellikleri aşağıda açıklanmıştır.

\section{a- SO4 ( V. Berlandieri X V. Riparia NO:4, Seleksiyon Oppenheimer NO:4)}

Başlangıçta hızlı bir gelişme gösteren kuvvetli bir anaçtır. SO4'ün aşı tutma oranı oldukça yüksektir. Ayrıca çelik çubuk elde etmek istendiğinde verimli olduğu ifade edilebilir (Çelik, 2011).

\section{b- 5BB ( V. Berlandieri X V. Riparia Teleki 8B, Seleksiyon Keber 5BB )}

Çelik oluşumu açısından yüksek verime sahiptir. 5BB'nin nemli ve killi topraklar için uygun olduğu ifade edilebilir. $\mathrm{Bu}$ anacın köklenmesi iyi olmasına karşın özellikle bağdaki aşılamalarda bazı sorunlar ortaya çıkmaktadır. Bağdaki bu anaca yapılan yarma aşılarında kalemden alışılmamış derecede kök oluşmakta ve bu durum daha sonra anacin ölmesine neden olmaktadır (Çelik, 2011).

\section{c- 8B ( V.Berlandieri X V.Riparia Teleki 8B)}

8B anacı genel anlamda dayanıklıdır. Kireçli 
topraklarda kullanılabilir ve nematodlara karşı da dayanıklıdır. Aşı tutma oranı yüksektir fakat köklenme oranı düşüktür (Çelik, 2011).

\section{d- Lot ( V.Rupestrisdu Lot St. George)}

Lot anacı ve üzerine aşılanan çeşit hızlı büyür. Yapraklarında gal oluşumu görülse de kökleri filoksera zararlısına karşı dayanıklıdır. Lot anacı kökleri derine gidebilir ve bu sayede sık sulanamayan kurak topraklarda kullanılabilir (Çelik, 2011).

\section{Metot}

Deneme deseni 3 tekerrürlü faktöriyel tasarımına göre kurulmuştur. Her tekerrüre 4 çelik alınmış, böylece her bir farklı anaç için 12 adet, toplam deneme için 48 adet çelik kullanılmıştır. Her anaçtan çelikler 4 boğumlu olarak seçilmiştir. Boyları $35 \mathrm{~cm}$ olacak şekilde çelikler hazırlanmış ve üst boğum dışarda kalacak şekilde $80 \mathrm{~cm}$ derinliğindeki kum sandıklarina $15 \times 15 \mathrm{~cm}$ aralık-mesafe ile saplama şeklinde dikilmiştir. Asma anacı fidanlarının sökülmesi sonbaharda (Kasım ayında) sürmüş ve yaprağını dökmüş tüm asma anacı fidanları sandıklar açılarak, oluşan köklere zarar vermeden, sökülüp tasnif edilmiştir (Can, 2019). Köklü asma anacı fidanındaki göz araştırmacıya doğru bakacak şekilde, asma anacı fidanlarında kök oluşum yerlerini saptamak amaciyla ölçümler boğumlardan ve boğum aralarından yapılmıştır. Bu bölgelerde oluşan kökler ise gözün solundan, sağından, karşısından ve hemen altından olmak üzere 4 farklı yönden kaydedilmiştir. Her bir yön için ortalama değer o boğumdan elde edilen ölçüm olarak analize dahil edilmiştir. Kök yoğunluğu, boğumlara ve asma anaçlarına göre ele alınmıştır. Boğumlarda da 2., 3. ve 4 . boğumdan elde edilen veriler araştırmaya konu edilmiştir. Boğum araları üst boğumun izdüşümü doğrultusunda çelikten çıkış yerlerinin tespitine dayansa da 2. ve 3 . boğum arası ile 3. ve 4. boğum arasında analize konu edilecek sayıda kök oluşumu gözlenmemiştir (Can, 2019).
Araştırmada Kök Yoğunluğunun Tespiti İçin İncelenen Kriterler

Asma anacı fidanlarından 4 yönden farklı boğumlardan ve anaç tiplerinden çıkan köklerde şu ölçümler yapılmıştır:

1. Kök sayısı (adet)

2. Kök uzunluğu $(\mathrm{cm})$

3. Kök ağırılığı (g)

4. Kök kalınlığı (mm)

Dört kritere dayalı dört farklı analiz yürütülmüştür. İki farklı faktörün (boğum ve anaç) ana etkileri ve etkileşim etkilerinin araştırılabildiği faktöriyel tasarım düzeni kullanılmıştır. Yalnız bir faktörün etkisini araştıran; tamamen rastgele tasarım (BirYönlü ANOVA)'dan daha etkili olan çok faktörlü tasarımlar her gözlemi ve bilgiyi kullanır. Faktör sayısının bir olduğu ve blok sayısına göre değişen tasarımlardan söz edilebilir. Bir faktör bir blok için rastgele tam blok tasarımı (İki-Yönlü ANOVA) ve bir faktör iki blok için latin kare (Üç-Yönlü ANOVA) tasarımı gibi tasarımlarda faktör sayısı birdir ve blok sayısı artmaktadır. Ayrıca iki faktörün ana etkilerinin yanında bu iki faktörün etkileşimlerinin de aynı zamanlı olarak sunulması çok faktörlü tasarımların avantajlarındandır. Sıklıkla faktörlerin düzeylerinin eşit olduğu $2^{\mathrm{k}}$, $3^{\mathrm{k}}$ gibi özel faktöriyel tasarımlarının yanında farklı faktör düzeylerinin olduğu genel faktöriyel tasarımları da kullanılabilir. $\mathrm{Bu}$ araştırmada anaç olarak çelik türü faktörü 4 düzeyde (SO4, 5BB, Lot ve 8B), boğum olarak köklenme olan boğum faktörü 3 farklı düzeyde (Boğum2, Boğum3 ve Boğum4) ele alınmıştır. Araştırmada kullanılan $4 \times 3$ faktöriyel tasarım modeli;

$y_{i j k}=\mu+\delta_{i}+\beta_{j}+\delta \beta_{i j}+\varepsilon_{i j k}$

$i=1,2,3,4 \quad j=1,2,3 \quad k=1,2,3,4$

şeklindedir. $y_{i j k}$ gözlem değeri, $\mu$ genel ortalama, $\delta_{i}$ köktipi faktörünün etkisi, $\beta_{j}$ boğum faktörünün etkisi, $\delta \beta_{i j}$ iki faktörün etkileşim etkisi ve $\varepsilon_{i j k}$ rasgale hata terimi olarak modelde yer almaktadır (Şenoğlu ve Acıtaş, 2011). Eşitlik 1'de sunulan genel modele dayalı 4 farklı modelse;

$$
\begin{array}{lllll}
\text { Model 1: } \text { koksayisi }_{i j k} & =\mu+\delta_{i}+\beta_{j}+\delta \beta_{i j}+\varepsilon_{i j k} & i=1,2,3,4 & j=1,2,3 & k=1,2,3,4 \\
\text { Model 2: } \text { kokuzunlugu }_{i j k}=\mu+\delta_{i}+\beta_{j}+\delta \beta_{i j}+\varepsilon_{i j k} & i=1,2,3,4 & j=1,2,3 & k=1,2,3,4 \\
\text { Model 3: } \text { kokagirligi }_{i j k} & =\mu+\delta_{i}+\beta_{j}+\delta \beta_{i j}+\varepsilon_{i j k} & i=1,2,3,4 & j=1,2,3 & k=1,2,3,4 \\
\text { Model 4: } \text { kokkalinligi }_{i j k} & =\mu+\delta_{i}+\beta_{j}+\delta \beta_{i j}+\varepsilon_{i j k} & i=1,2,3,4 & j=1,2,3 & k=1,2,3,4
\end{array}
$$

şeklindedir. Her bir model için sıfir hipotezleri ise;

$H_{01}: \delta_{1}=\delta_{2}=\delta_{3}=\delta_{4}=0$ veya $H_{01}$ : Anaç kök sayısını etkilemez

$H_{02}: \beta_{1}=\beta_{2}=\beta_{3}=0$ veya $H_{02}$ : Boğum yeri kök sayısını etkilemez

$H_{03}: \delta \beta_{11}=\delta \beta_{12}=\cdots=\delta \beta_{43}=0 \quad$ veya $\quad H_{03}: \quad$ İkili etkileşimler kök sayısını etkilemez

şeklinde kurulur. $H_{01}$ hipotezi anaç faktörünün, $H_{02}$ hipotezi boğum faktörünün ve $H_{03}$ ise anaç $x$ boğum etkileşiminin anlamlı olup olmadığını sınamak için kullanılır. Her birinin alternatifi ise en az bir katsayının 0'dan farklı olduğu şeklindedir. Dolayısıyla 12 yokluk hipotezi ve 12 alternatif hipotez söz konusudur. Analizler SPSS programında yapılmıştır.

\section{BULGULAR ve TARTIŞMA}

Yürütülen çalışmalar sonunda elde edilen analizler 
her bir model için ayrı ayrı ele alınmıştır. Kök sayısı için yürütülen analizler Çizelge 1'de sunulmuştur.

Yapılan variyans analizi sonuçlarına göre anaçların kök sayısı için fark oluşturmadığı ancak boğumların kök sayısı için istatistiksel anlamda farklı olduğu sonucuna ulaşılmıştır. Ayrıca etkileşimin yani iki ana etkinin beraber kök sayısı bakımından farklı seviyelerde farklı sonuçlar verdiği (katsayıların 0'dan istatistiksel olarak farklı olduğu) ortaya konmuştur.

Kök uzunluğu için yürütülen analizler Çizelge 2'de sunulmuştur.
$\mathrm{Bu}$ analizlere dayalı olarak anaçların ve boğumların kök uzunluğunda etkili olduğu sonucuna ulaşılmıştır. Ayrıca etkileşimin de kök uzunluğu bakımından farklı seviyelerde farklı sonuçlar verdiği yani katsayıların 0'dan istatistiksel olarak farklı olduğu ortaya konmuştur.

Kök ağırlığı için yürütülen analizler Çizelge 3'de sunulmuştur.

$\mathrm{Bu}$ analizlere dayalı olarak ana etki olan anacın ve boğumun yanı sıra etkileşimin kök ağırlığı üzerinde etkili olduğu sonucuna ulaşılmıştır.

Çizelge 1. Kök sayısı için varyans analizi sonuçları

Table 1. Variance analysis results for the number of roots

\begin{tabular}{|c|c|c|c|c|c|}
\hline $\begin{array}{c}\text { Değişimin Kaynağı } \\
\text { (Source) }\end{array}$ & $\begin{array}{l}\text { Kareler Top. } \\
\text { (Sum Sq.) }\end{array}$ & $\begin{array}{c}\text { Serbestlik Der. } \\
(D F)\end{array}$ & $\begin{array}{l}\text { Kareler ort. } \\
\text { (Mean Sq.) }\end{array}$ & $\mathrm{F}$ & $\begin{array}{l}\mathrm{p} \text {-değeri } \\
(p \text {-value })\end{array}$ \\
\hline Sabit (Intercept) & 1077.023 & 1 & 1077.023 & 407.783 & .000 \\
\hline Anaç (Grap. Typ.) & 11.402 & 3 & 3.801 & 1.439 & .247 \\
\hline Boğum (Internodes) & 30.021 & 2 & 15.011 & 5.683 & .007 \\
\hline $\begin{array}{l}\text { Anaç } x \text { Boğum } \\
\text { (Grap. Typ. } x \text { Internodes) }\end{array}$ & 113.917 & 6 & 18.986 & 7.189 & .000 \\
\hline Hata (Error) & 95.082 & 36 & 2.641 & & \\
\hline Genel (Total) & 1327.446 & 48 & & & \\
\hline
\end{tabular}

Çizelge 2. Kök uzunluğu için varyans analizi sonuçları

Table 2. Variance analysis results for root length

\begin{tabular}{|c|c|c|c|c|c|}
\hline $\begin{array}{l}\text { Değişimin Kaynağ } \\
\text { (Source) }\end{array}$ & $\begin{array}{l}\text { Kareler Top. } \\
\text { (Sum Sq.) }\end{array}$ & $\begin{array}{c}\text { Serbestlik Der. } \\
(D F)\end{array}$ & $\begin{array}{r}\text { Kareler ort. } \\
\text { (Mean Sq.) }\end{array}$ & $\mathrm{F}$ & $\begin{array}{l}\mathrm{p} \text {-değeri } \\
\text { ( } p \text {-value })\end{array}$ \\
\hline Sabit (Intercept) & 8105.761 & 1 & 8105.761 & 624.833 & .000 \\
\hline Anaç (Grap. Typ.) & 466.044 & 3 & 155.348 & 11.975 & .000 \\
\hline Boğum (Internodes) & 85.732 & 2 & 42.866 & 3.304 & .048 \\
\hline $\begin{array}{l}\text { Anaç } x \text { Boğum } \\
\text { (Grap. Typ. } x \text { Internodes) }\end{array}$ & 570.343 & 6 & 95.057 & 7.327 & .000 \\
\hline Hata (Error) & 467.017 & 36 & 12.973 & & \\
\hline Genel (Total) & 9694.897 & 48 & & & \\
\hline
\end{tabular}

Çizelge 3. Kök ağırlık için varyans analizi sonuçları

Table 3. Variance analysis results for root weight

\begin{tabular}{lccccc}
\hline $\begin{array}{c}\text { Değişimin Kaynağ } \\
\text { (Source) }\end{array}$ & $\begin{array}{c}\text { Kareler Top. } \\
\text { (Sum Sq.) }\end{array}$ & $\begin{array}{c}\text { Serbestlik Der. } \\
\text { (DF) }\end{array}$ & $\begin{array}{c}\text { Kareler ort. } \\
\text { (Mean Sq.) }\end{array}$ & $\begin{array}{c}\mathrm{F} \text {-değeri } \\
(p \text {-value) }\end{array}$ \\
\hline Sabit (Intercept) & 26.285 & 1 & 26.285 & 724.820 & .000 \\
Anaç (Grap. Typ.) & .699 & 3 & .233 & 6.428 & .001 \\
Boğum (Internodes) & .278 & 2 & .139 & 3.827 & .031 \\
Anaç $\boldsymbol{x}$ Boğum & 2.055 & 6 & .343 & .000 \\
(Grap. Typ. $\boldsymbol{x}$ Internodes) & & & & .036 & \\
Hata (Error) & 1.306 & 36 & & \\
Genel (Total) & 30.623 & 48 & & \\
\hline
\end{tabular}

Kök kalınlığı için yürütülen analizler Çizelge 4'de sunulmuştur. $\mathrm{Bu}$ analizlere dayalı olarak da diğer yoğunluk kriterlerinin olduğu gibi son kriter olan kök kalınlığ 1 için de ana etkiler ve etkileşim etkisi anlamlıdır. Bu analizlerin yanında faktör düzeylerinin ortalamaları çoklu karşılaştırma testleri ile kıyaslanabilir. Bu araştırmada Fisher'in en küçük anlamlı fark (LSD) testi kullanılmıştır. Sonuçlar Çizelge 5’te sunulmuştur.
Çizelge 5'e göre SO4 ile 5B arasında kalınlık, SO4 ile Lot arasında uzunluk ve kalınlık, SO4 ile 8B arasında uzunluk ve ağırlık, 5BB ile Lot arasında kalınlık, 5BB ve $8 \mathrm{~B}$ arasında uzunluk, ağırlık ve kalınlık, Lot ve $8 \mathrm{~B}$ arasında uzunluk, ağırlık ve kalınlık bakımından fark vardır. Ayrıca boğum 2 ile boğum 3 arasında uzunluk, ağırlık ve kalınlık, boğum 2 ile boğum 4 arasında sayı ve kalınlık, boğum 3 ile boğum 4 arasında ise sayı, uzunluk, ağırlık ve kalınlık bakımından fark vardır. 
Literatürde de farklı anaçların köklenme açısından farklılıklar gösterdiğini destekleyen çalışmalar mevcuttur (Atilla, 1985; Barış, 1983; Barlass ve Skene, 1980). Boğumlar açısından da dip boğumlarda kök sayısının arttığı gözlemlenmiştir. Bu sonuç köklenme özelliklerinin anaçlara göre değiştiği bilgisini (Çakır ve ark., 2013), aynı anacın üzerinde de değişebileceği bilgisiyle geliştirmektedir. Anaç-kalem kombinasyonunun (Santarosa ve ark., 2015), kültür ortamının (Şengel ve Ark., 2012), kallus oluşumu, köklenme kapasitesi ve anaç farklılıklarının (Cangi ve Etker, 2018), toprak ortamları ve anaç genotiplerinin (Smart ve Ark., 2006) etkileri incelenmiştir. Bu çalışmada da eş kültür ortamında farklı anaçların ve boğumların istatistiksel anlamda farklı kök yoğunluklarına sahip olduğu ortaya konmuştur.

Çizelge 4. Kök kalınlığı için varyans analizi sonuçları

Table 4. Variance analysis results for root thickness

\begin{tabular}{lccccc}
\hline \multicolumn{1}{c}{$\begin{array}{c}\text { Değişimin Kaynağ } \\
\text { (Source) }\end{array}$} & $\begin{array}{c}\text { Kareler Top. } \\
\text { (Sum Sq.) }\end{array}$ & $\begin{array}{c}\text { Serbestlik Der. } \\
(D F)\end{array}$ & $\begin{array}{c}\text { Kareler ort. } \\
(\text { Mean } S q .)\end{array}$ & $\begin{array}{c}\text { p-değeri } \\
(p \text {-value })\end{array}$ \\
\hline Sabit (Intercept) & 29.110 & 1 & 29.110 & 746.588 & .000 \\
Anaç (Grap. Typ.) & 3.925 & 3 & 1.308 & 33.560 & .000 \\
Boğum (Internodes) & 2.513 & 2 & 1.256 & 32.225 & .000 \\
Anaç $x$ Boğum & 5.117 & 6 & .853 & 21.873 & .000 \\
(Grap. Typ. $x$ Internodes) & & & & & \\
Hata (Error) & 1.404 & 36 & & & \\
Genel (Total) & 42.069 & 48 & & & \\
\hline
\end{tabular}

Çizelge 5. Anaçlar ve boğumlar için en küçük anlamlı fark testi sonuçları

Table 5. Results of Fisher's least significant difference (LSD) test for root type and internodes

\begin{tabular}{|c|c|c|c|c|c|}
\hline & & \multicolumn{2}{|c|}{ Kök Sayısı (Number of Roots) } & \multicolumn{2}{|c|}{ Kök Sayısı (Number of Roots) } \\
\hline & İkililer (Compared Groups) & $\begin{array}{l}\text { Ortalama Fark } \\
\text { (Mean Difference) }\end{array}$ & $\begin{array}{l}\mathrm{p} \text {-değeri } \\
(p \text {-value })\end{array}$ & $\begin{array}{l}\text { Ortalama Fark } \\
\text { (Mean Difference) }\end{array}$ & $\begin{array}{l}\mathrm{p} \text {-değeri } \\
(p \text {-value })\end{array}$ \\
\hline \multirow{6}{*}{ 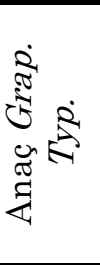 } & $\mathrm{SO} 4 \mid 5 \mathrm{BB}$ & -0.2542 & 0.704 & -0.9725 & 0.513 \\
\hline & SO4 | Lot & -0.4658 & 0.487 & -3.8558 & 0.013 \\
\hline & $\mathrm{SO} 4 \mid 8 \mathrm{~B}$ & -0.8192 & 0.225 & -4.7983 & 0.002 \\
\hline & $5 \mathrm{BB} \mid$ Lot & -0.2117 & 0.752 & -2.8833 & 0.058 \\
\hline & $5 \mathrm{BB} \mid 8 \mathrm{~B}$ & 1.0733 & 0.114 & 5.7708 & 0.000 \\
\hline & Lot $\mid 8 \mathrm{~B}$ & 1.2850 & 0.061 & 8.6542 & 0.000 \\
\hline \multirow{5}{*}{ 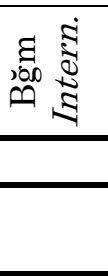 } & B2|B3 & 0.3194 & 0.582 & 2.8425 & 0.032 \\
\hline & $\mathrm{B} 2 \mid \mathrm{B} 4$ & -1.4950 & 0.013 & 0.0150 & 0.991 \\
\hline & $\mathrm{B} 3 \mid \mathrm{B} 4$ & -1.8144 & 0.003 & -2.8275 & 0.033 \\
\hline & & \multicolumn{2}{|c|}{ Kök Ağırlığı Root Weight } & \multicolumn{2}{|c|}{ Kök Kalınlığ 1 Root ThicknesS } \\
\hline & İkililer (Compared Groups) & $\begin{array}{l}\text { Ortalama Fark } \\
\text { (Mean Difference) }\end{array}$ & $\begin{array}{l}\mathrm{p} \text {-değeri } \\
\text { ( } p \text {-value })\end{array}$ & $\begin{array}{l}\text { Ortalama Fark } \\
\text { (Mean Difference) }\end{array}$ & $\begin{array}{l}\mathrm{p} \text {-değeri } \\
(p \text {-value })\end{array}$ \\
\hline \multirow{6}{*}{ 苞 } & $\mathrm{SO} 4 \mid 5 \mathrm{BB}$ & -0.0458 & 0.559 & -0.2467 & 0.004 \\
\hline & SO4|Lot & 0.0442 & 0.573 & -0.6183 & 0.000 \\
\hline & $\mathrm{SO} 4 \mid 8 \mathrm{~B}$ & 0.2683 & 0.001 & 0.1333 & 0.107 \\
\hline & $5 \mathrm{BB} \mid$ Lot & 0.0900 & 0.255 & -0.3717 & 0.000 \\
\hline & $5 \mathrm{BB} \mid 8 \mathrm{~B}$ & 0.3142 & 0.000 & 0.3800 & 0.000 \\
\hline & Lot $\mid 8 \mathrm{~B}$ & 0.2242 & 0.007 & 0.7517 & 0.000 \\
\hline \multirow{3}{*}{ 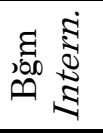 } & B2|B3 & 0.1500 & 0.032 & 0.1494 & 0.039 \\
\hline & $\mathrm{B} 2$ |B4 & -0.0206 & 0.761 & -0.3931 & 0.000 \\
\hline & B3|B4 & -0.1706 & 0.016 & -0.5425 & 0.000 \\
\hline
\end{tabular}

\section{SONUÇ}

Yürütülen analizler sonunda dört düzeyli anaç ana etkisinin kök sayısı hariç diğer tüm yoğunluk kriterleri için anlamlı olduğu ifade edilebilir. Ayrıca üç düzeyli boğum ana etkisi ve anaç ile boğum ana etkilerinin etkileşimi istatistiksel olarak her modelde yine anlamlıdır. Buradan hareketle anaçların kök oluşum yoğunluğu üzerinde etkili olduğu hipotezi istatistiksel bulgular ile desteklenmiş ve ortaya konmuştur. Anaç faktörü açısından Boğum2'de, 5BB ve SO4 ilgili kriterlere göre baskındır. Boğum3'de SO4 ve $8 \mathrm{~B}$ üstünlüğü ilgili kriterlere göre gözlemlenmiştir, $8 \mathrm{~B}$ ise oldukça yoğun köklenme sağlayarak $\mathrm{SO} 4$ ve 8B'yi takip etmiştir. Boğum4'de ise $8 \mathrm{~B}$ kalınlık ve uzunluk açısından yoğun köklenme oluştururken Lot uzunluk, kalınlık ve ağırlık yönünden yoğun köklenme sağlamıştır. Kök yerlerinin kök oluşum yoğunluğu açısından ele alınmasıyla da boğumlar arası 
istatistiksel olarak farklılıklar olduğu ortaya konmuştur. Boğum faktörü için dip boğumlarda daha yoğun kök oluşmuştur. İstatistiksel bulgular da farklı boğumlarda farklı kök yoğunluklarının olduğunu desteklemektedir. Ayrıca boğumlar arası kök oluşumunun oldukça zayıf olduğu ortaya konmuştur. Boğumlar üzerinde çıkan köklerin de yönlere göre farklılaşmadığı gözlemlenmiştir.

\section{TEŞEKKÜR}

$\mathrm{Bu}$ çalışma Fatime Can'ın yüksek lisans tez araştırmaları için oluş̧urulan deney düzeninden elde edilen veriler ile yürütülmüştür. Bitkisel materyal temini için Tekirdağ Bağcılık ve Araştırma Enstitüsü’ ne teşekkür ederiz.

\section{Çıkar Çatışması Beyanı}

Makale yazarları aralarında herhangi bir çıkar çatışması olmadığını beyan ederler.

\section{Araştırmacıların Katkı Oranı Beyan Özeti}

Yazarlar makaleye eşit oranda katkı sağlamış olduklarını beyan ederler.

\section{KAYNAKLAR}

Anonim 1983. Asma Fidanı Standardı. TS3981/Nisan 1983. Türk Standartları Enstitüsü, Ankara.

Anonim 1988. Bağcılık-Aşlama Metod ve Kuralları Standardı. TS625/Aralık 1988. Türk Standartları Enstitüsü, Ankara.

Anonim 1990. Bağcılık Terbiye Sekil ve Kuralları. TS8465/Nisan 1990. Türk Standartları Enstitüsü, Ankara.

Anonim 1992. Budama Metod ve Kuralları. TS10130/Nisan 1992. Türk Standartları Enstitüsü, Ankara.

Aslan K A, Özcan S, Kösetürkmen S, Yağcı A, Sakar E, Bekişli M İ, Kılıç D 2015. Gaziantep İlinde Asma Fidanı Üretiminde Farklı Çeşit-Anaç Kombinasyonlarının Karşılaştırılması. Selçuk Üniversitesi Selçuk Tarım ve Gıda Bilimleri Dergisi-A 27(Türkiye 8. Bağcllık ve Teknolojileri Sempozyumu Özel Sayısı): 210-216.

Atilla A 1985. Bağ Dikiminde Mekanizasyon. Türkiye 1. Bağcılık Sempozyumu Bildirileri Cilt: 1, Tarım, Orman ve Köy İşleri Bakanlığı Yayınları 3: 177187.

Barış C 1983. Yurdumuzda Kullanılan Asma Anaçları ve Özellikleri. Tekirdağ Bağcılık Enst. Yayınları 24(3): 24-33.

Barlass M, Skene K G M 1980. Studies on The Fragmented Shoot Apex of Grapevine. II. Factors Affecing Growth and Differentiantion in Vitro. Journal of Experimental Botany 31(121): 489-495.

Can F 2019. Asma Anacı Çeliklerinde Kök Oluşum Yoğunluğu Yerlerinin Belirlenmesi. Tekirdağ Namık Kemal Üniversitesi Fen Bilimleri Enstitüsü
Bahçe Bitkileri Ana Bilim Dalı, Yüksek Lisans Tezi, 32 sy.

Cangi R, Etker M 2018. The Effects of Rootstock Cutting Thickness on Final Take, Quality of Potted Grapevine Saplings. YYU J Agr Sci 28(özel sayı): 50-56

Çakır A, Karaca N, Sidfar M, Baral Ç, Söylemezoğlu G 2013. Sultani Çekirdeksiz Üzüm Çeşidinin Farklı Amerikan Asma Anaçları ile Aşı Tutma Oranının Belirlenmesi. YYÜ Tar Bil Derg 23(3):229-235.

Çelik H, Ağaoğlu Y S, Fidan Y, Marasalı B, Söylemezoğlu G 1998. Genel Bağcılık. Sun Fidan A.Ş., Mesleki Kitaplar Serisi:1. Fersa Matbaacılık San. ve Tic. Ltd. Şti., Ankara, 253 sy.

Çelik S 2011. Bağcılık (Ampeloloji). Namık Kemal Üniversitesi, Ziraat Fakültesi, Bahçe Bitkileri Bölümü Cilt 1, 3. Baskı Tekirdağ 423 sy.

Eroğlu D, Çelik M 2015. Bazı Üzüm Çeşitlerinin Aşılı Asma Fidanı Üretiminde Mikorize Uygulamalarının Etkileri. Selçuk Üniversitesi Selçuk Tarım ve Gıda Bilimleri Dergisi-A 27(Türkiye 8. Bağcılık ve Teknolojileri Sempozyumu Özel Sayısı): 48-55.

İşçi B, Altındişli, A, Kacar E, Yıldız D, Soltekin O, Önder S, Ünal A, Savaş Y 2015. Farklı Asma Anaçları ile Aşılı Red Globe Üzüm Çeşidinin Fidan Randımanı Üzerine Bir Çalışma. Selçuk Üniversitesi Selçuk Tarım ve Gıda Bilimleri Dergisi-A 27 (Türkiye 8. Bağcllık Ve Teknolojileri Sempozyumu Özel Sayısı): 17-26.

Köse B, Çelik H, Karabulut B 2015. Determination of callusing performance and vine sapling characteristics on different rootstocks of 'Merzifon Karası' grape variety (Vitis vinifera L.). Anadolu Tarım Bilim. Derg./Anadolu J Agr Sci, 30: 87-94.

Persuric D, Bubola M, Sradeka S 2015. Influence of Bud Number per Vine on Istrian Malvasia Yield Characteristics Grafted on Different Rootstock. 50. Croatian and 10. International Symposium on Agriculture 16-20 Şubat 2015, Croatia.

Ruckenbauer W, Traxler H, Vas S, Leuchtner R 1975. Weinbau Heute: Handbuch Für Beratung, Schulung und Praxis. L. Stocker, 608 sy.

Sabır A 2002. Tüplü asma fidanı üretiminde değişik IBA ve NAA uygulamalarının farklı çeşit/anaç kombinasyonlarında fidan randımanına etkileri üzerinde bir araştırma. Selçuk Üniversitesi Fen Bilimleri Enstitüsü Bahçe Bitkileri Anabilim Dalı, Yüksek Lisans Tezi, 66 sy.

Santarosa E, Souza P V, Mariath J E, Lourosa G V 2015. Physiological interaction between rootstockscion: effects on xylem vessels in Cabernet Sauvignon and Merlot grapevines American Journal of Enology and Viticulture 67 (1): 65-76.

Smart D R, Schwass E, Lakso A, Morano L 2006. Grapevine rooting patterns: A comprehensive analysis and a review. American Journal of Enology and Viticulture 57(1):89-104. 
SPSS 2013. IBM SPSS Statistics 21.0 for Windows. Armonk, NY.

Sucu S, Yağcı A 2017. Bazı Asma Anaçları Üzerine Aşılı Sultani Çekirdeksiz Çeşidinde Fidan Randımanı ve Kalite Özelliklerinin Belirlenmesi. Ege Üniv. Ziraat Fak. Derg., 54(1):53-59.

Şengel E, İşçi B, Altındişli A 2012. Effects of Different Culture Media on Rooting in Grafted Grapevine. Ege Üniv. Ziraat Fak. Derg., 49 (2): 143-148.

Şenoğlu B, Acıtaş Ş 2011. İstatistiksel Deney
Tasarımı: Sabit Etkili Modeller. 2. Basım. Nobel Yayın Dağıtım, Ankara, 390 sy.

Yağcı A, Aydin S 2015. Açık Köklü Asma Fidanı Üretiminde Farklı Gölgeleme Oranlarının Fidan Randıman ve Kalitesine Etkileri. Selçuk Tarım ve Gida Bilimleri Dergisi, 27:146-153.

Yağcı A, Gökkaynak A G 2016. Sultani Çekirdeksiz Üzüm Çeşidinin Fidan Randımanı ve Kalitesi Üzerine Anaç ve Gölgeleme Oranının Etkisi. Ege Üniv. Ziraat Fak. Derg., 53(1): 109-116. 